\section{Estudo farmacognóstico de galhos de Vanillosmopsis erythropappa Schult. Bip. - Asteraceae}

\author{
Souza, O.V.S. ${ }^{\star}$; Oliveira, M.S.; Rabello, S.V.; Cunha, R.O.; Costa, \\ B.L.S.; Leite, M.N.
}

Departamento Farmacêutico, Faculdade de Farmácia e Bioquímica, Universidade Federal de Juiz de Fora.

\section{Resumo}

Vanillosmopsis erythropappa é um vegetal rico em óleos essenciais, especialmente o $\alpha$-bisabolol. O objetivo deste estudo foi pesquisar a variação sazonal qualitativa de substâncias naturais, teores de óleos essenciais, cinzas totais, umidade e $\mathrm{pH}$. Os resultados mostraram uma variação de flavonóides, taninos, triterpenóides, esteróides, saponinas, óleos essenciais, cinzas totais, umidade e $\mathrm{pH}$, demonstrando que os aspectos ambientais influenciam o metabolismo dessa espécie. As médias anuais dos valores obtidos foram: óleos essenciais $=0,29 \pm 0,09 \%$; cinzas totais $=3,13 \pm 0,49 \%$; umidade $=$ $6,56 \pm 0,80 \%$ e $\mathrm{pH}=5,40 \pm 0,24$.

\section{Abstract}

Vanillosmopsis erythropappa is a plant rich in essential oils, especially $\alpha$-bisabolol. The aim of this study was research the qualitative seasonal variation of natural substances, tenor of essential oils, total ashes, dampness and $\mathrm{pH}$. The results showed a variation of the flavonoids, tannins, triterpenoids, steroids, saponins, essential oils, total ashes, dampness and $\mathrm{pH}$, demonstrating that environmental aspects influence on the metabolism of this specie. The annual averages of the obtained values were: essential oils $=0,29 \pm 0,09 \%$; total ashes $=3,13 \pm$ $0,49 \%$; dampness $=6,56 \pm 0,80 \%$ and $\mathrm{pH}=5,40 \pm 0,24$.

A família Asteraceae compreende cerca de 1100 gêneros, com aproximadamente 25000 espécies, encontradas em regiões tropicais, subtropicais e temperadas, sendo mais abundantes nas regiões áridas do que nas florestas tropicais úmidas. No Brasil estão representadas por cerca de 180 gêneros ${ }^{1}$. $\mathrm{Na}$ grande maioria, as espécies de Asteraceae estão representadas por vegetais herbáceos, anuais ou perenes, subarbustivos ou arbustivos e só raramente, por vegetais arbóreos. As espécies do gênero Vanillosmopsis são exemplos de asteráceas arbóreas ${ }^{1}$.

Vanillosmopsis erythropappa Schult. Bip. é conhecida popularmente como candeia-da-serra, é encontrada no alto das Serras da Mantiqueira e Espinhaço e pode ser reconhecida pelos capítulos róseos, que exercem grande atração para os polinizadores. Após serem polinizados, os capítulos produzem centenas de pequenos frutos, que são dispersos pelo vento ou animais, para outras áreas distantes da planta-mãe, assegurando a perpetuação da espécie ${ }^{4,7}$.
Essa espécie cresce geralmente em solos rasos e pobres, em afloramentos, suas raízes se desenvolvem entre as fendas de rochas e os ramos tornam-se tortuosos e com casca grossa. Numerosos líquens foliáceos como, por exemplo, Usnea barbata ("Barba-de Velho"), crescem sobre a casca como suporte e podem atingir alguns metros de comprimento ${ }^{7}$.

A candeia apresenta um grande potencial econômico, não somente pelo uso tradicional de sua madeira, de alta resistência e durabilidade, mas também por possuir óleos essenciais ( $\alpha$-bisabolol exportado para indústrias de cosméticos e farmacêuticas da Alemanha e do Japão) responsáveis pelo cheiro característico na queima. Esses óleos exibem propriedades antiflogística, antibacteriana, antimicótica e dermatológica ${ }^{3}$.

Do óleo da madeira, foram isoladas as lactonas sesquiterpênicas eremantina, goyazensolide, 15desoxigoyazensolide, lychnofolide, costunolide e bisabolol ${ }^{2,14}$. Além disso, triagem fitoquímica das inflorescências de Vanillomopsis erythropappa demonstrou a presença de flavonóides, taninos, cumarinas, terpenóides, esteróides e saponinas. Bioensaios com Artemia salina mostraram que os extratos hexânico e diclorometânico desse vegetal são tóxicos ${ }^{8,9}$ e que os extratos hexânico, diclorometânico, de acetato de etila e butanólico possuem atividade antibacteriana sobre Streptococcus pyogenes e Staphylococcus aureus ${ }^{12}$.

Visando dar uma contribuição ao estudo farmacognóstico da espécie Vanillosmopsis erythropappa Schult. Bip., este trabalho tem o intuito de pesquisar a presença de constituintes do metabolismo secundário, determinar os teores de óleo essencial, cinzas totais, umidade e $\mathrm{pH}$ em galhos coletados nos meses do ano de 2001.

A tabela 1 mostra que os flavonóides, taninos, triterpenóides, esteróides e saponinas variaram qualitativamente ao longo dos meses do ano de 2001. Foi observada uma maior intensidade nas reações para flavonóides nos meses correspondentes ao verão. Essa intensidade pode ser devido à função desses constituintes de proteger os vegetais contra a incidência de raios ultravioleta e visível, além de proteger contra insetos, fungos, vírus e bactérias. As reações para os taninos foram menos acentuadas do que para os flavonóides. Os taninos estão envolvidos na defesa química das plantas contra o ataque de herbívoros ou invertebrados e contra microorganismos patogênicos, o que pode explicar o aumento da intensidade em alguns meses ${ }^{10}$ (tabela 1 ).

As reações para triterpenóides e esteróides foram mais intensas entre os meses de junho e setembro, enquanto as intensidades das reações para saponinas (índice de espuma) foram mais significativas entre os meses de janeiro a abril. É possível que tenha ocorrido um desvio da rota metabólica nesses períodos, ou seja, como os heterosídeos, esteróides e as saponinas são provenientes da via do mevalonato, as mudanças do meio ambiente produziram alterações na via biossintética ${ }^{10}$ (tabela 1 e figura 1 ).

Foi detectada a presença de cumarina nas amostras analisadas, entretanto, não houve alteração qualitativa nos meses pesquisados. As reações para alcalóides e antraquinonas foram negativas, demonstrando que Vanillosmopsis 
erythropappa não desvia sua rota metabólica para essas classes de constituintes (tabela 1).

Tabela 1. Variação sazonal qualitativa de classes de substâncias do metabolismo secundário de galhos de Vanillosmopsis erythropappa.

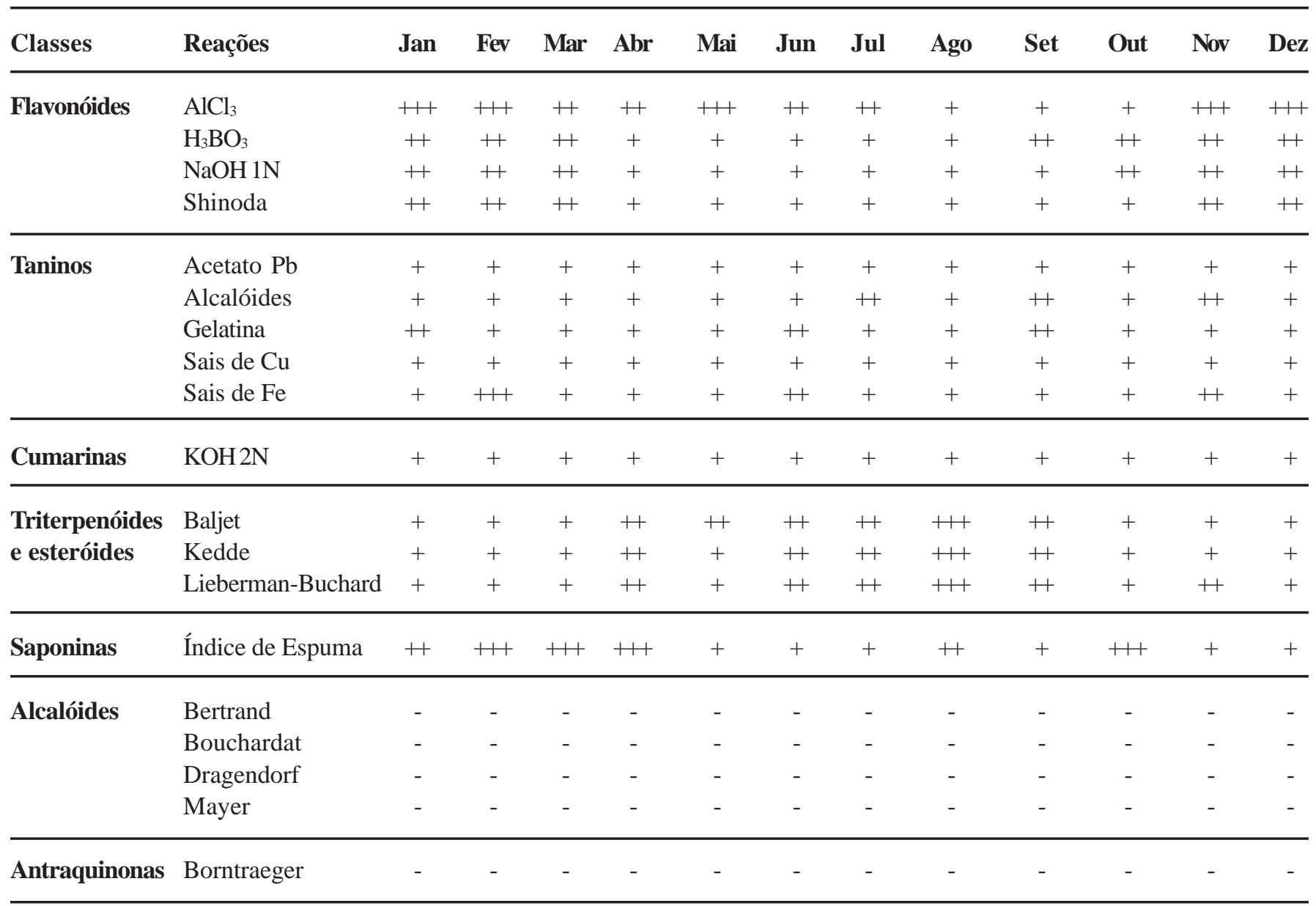

(-) ausência da reação e (+) intensidade da reação.

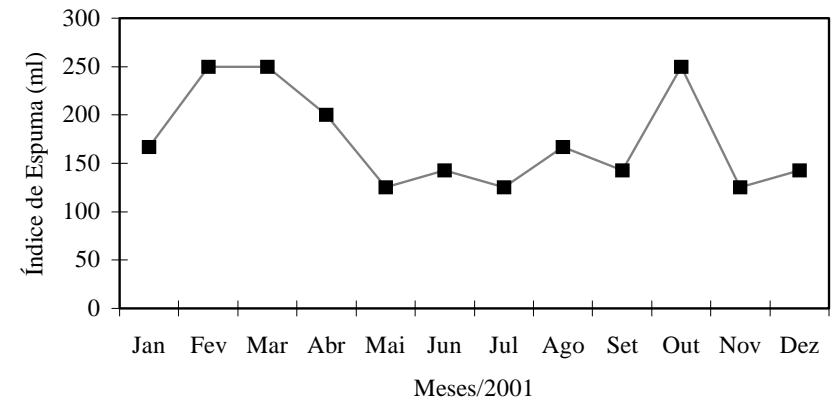

Figura 1. Variação sazonal quantitativa de saponinas pela análise do índice de espuma.

\section{Variação sazonal quantitativa de óleos essenciais e cinzas totais de galhos de Vanillosmopsis erythropappa}

Foi observado que Vanillosmopsis erythropappa produziu um maior teor de óleos essenciais nos meses correspondentes à primavera e ao verão (janeiro, fevereiro, março, outubro, novembro e dezembro) (figura 2). Isso demonstra que o aumento da temperatura favorece uma maior biossíntese desses constituintes, o que implica nas funções dos óleos essenciais de proteger a planta contra predadores, de atrair polinizadores, de proteger a planta contra perda de água e aumento da temperatura ${ }^{10}$. Ao contrário, entre os meses de abril a agosto, que são menos quentes, houve uma redução na biossíntese de óleos essenciais, demonstrando mais uma vez que as condições climáticas estão influenciando o metabolismo da planta.

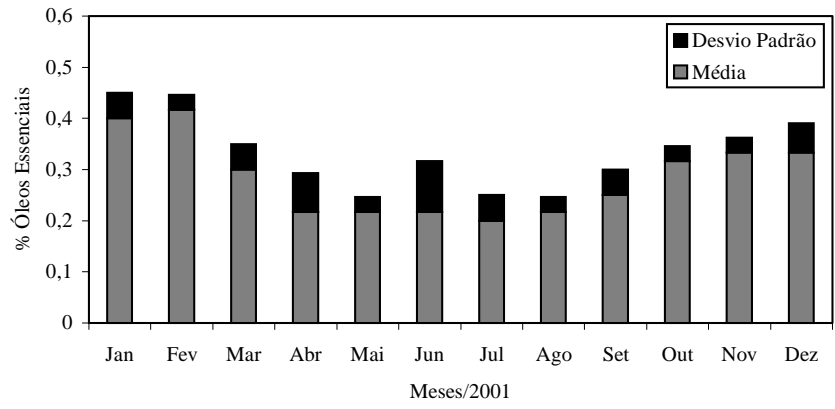

Figura 2. Variação sazonal de óleos essenciais das amostras analisadas durante os meses de 2001 
A determinação do teor de cinzas totais de um vegetal constitui um ensaio de pureza para verificar impurezas inorgânicas não-voláteis, que podem estar presentes como contaminantes ${ }^{10}$. Isso significa que essa determinação é uma referência de qualidade e caracterização de um vegetal. Por isso, o intuito desse estudo foi estabelecer o parâmetro de cinzas totais para Vanillosmopsis erythropappa, visto que o mesmo ainda não foi descrito na literatura.

Diante dos resultados obtidos, o teor de cinzas totais variou de 2,47 a 4,20\% com uma média anual de 3,13 $\pm 0,49 \%$ (figura 3). Os meses de outubro, novembro e dezembro foram mais significativos, produzindo em média $3,48 \pm 0,04 \%, 4,15 \pm$ $0,06 \%$ e $3,77 \pm 0,05 \%$, respectivamente. Comparando com outras espécies citadas na literatura, esses valores se encontram dentro do esperado (figura 3 ).

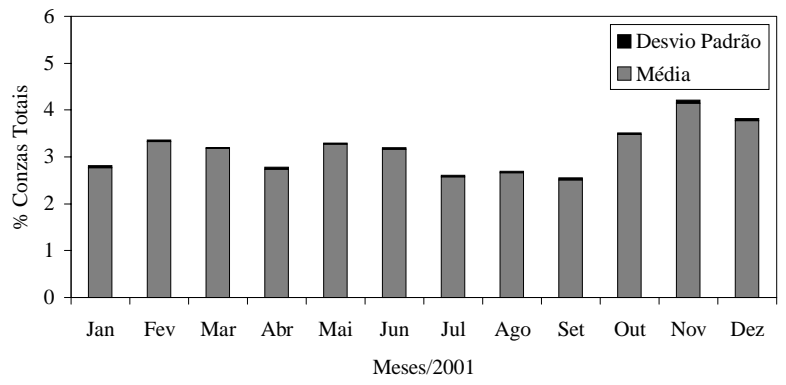

Figura 3. Variação sazonal de cinzas totais das amostras analisadas durante os meses de 2001.

$\mathrm{O}$ excesso de umidade em matérias-primas vegetais permite a ação de enzimas, podendo acarretar a degradação de constituintes químicos, além de possibilitar o desenvolvimento de fungos e bactérias. $\mathrm{O}$ teor de umidade estabelecido nas diferentes farmacopéias varia de 8 a $14 \%$, com poucas exceções especificadas nas monografias ${ }^{10}$. Além disso, para realização de estudos fitoquímicos é recomendado que haja uma perda de 90 a $95 \%$ da umidade da planta. Portanto, assim como na determinação do teor de cinzas totais, a quantificação do teor de umidade serve como parâmetro para estabelecer a qualidade das matérias-primas vegetais.

De acordo com os resultados obtidos, o teor de umidade para Vanillosmopsis erythropappa durante o ano de 2001 variou de 5,20 a 8,00\% com uma média anual de 6,56 $\pm 0,80$ $\%$ (figura 4). Dessa forma, o material de Vanillosmopsis erythropappa se encontra dentro dos valores estabelecidos nesse estudo.

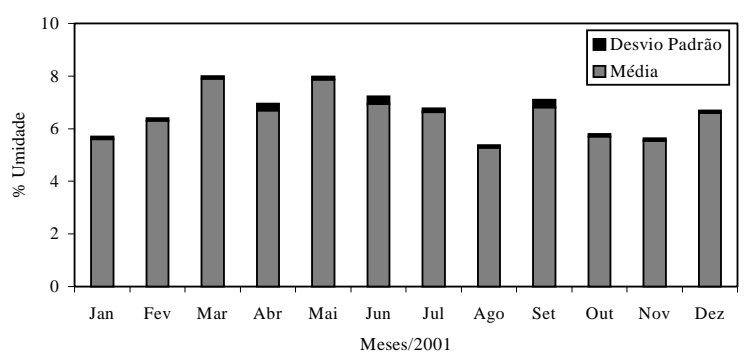

Figura 4. Variação sazonal do teor de umidade das amostras analisadas durante os meses de 2001.
Uma das importâncias do pH nos vegetais está no mecanismo de formação de ATP, que é impulsionado por uma força próton-motriz durante a fotofosforilação nos cloroplastos. O ATP é uma molécula de alta energia, que acopla reações não favoráveis no interior das células. Entre essas reações, estão entre aquelas que fazem parte da biossíntese de enzimas importantes no metabolismo secundário. Além disso, as alterações metabólicas provocadas por reações de óxido-redução podem modificar o $\mathrm{pH}$ das células vegetais, promovendo desvio da rota do metabolismo ${ }^{13}$.

De acordo com os dados da figura 5, o pH mínimo encontrado foi 5,03 e o máximo de 5,88, demonstrando que o material analisado possui um $\mathrm{pH}$ ácido.

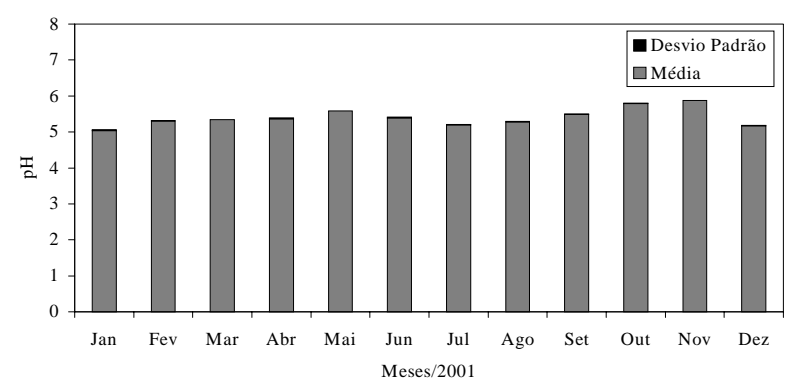

Figura 5. Variação sazonal do $\mathrm{pH}$ das amostras analisadas durante os meses de 2001.

Os resultados desta pesquisa indicam que ocorreu uma variação sazonal qualitativa dos constituintes flavonóides, taninos, triterpenóides, esteróides, saponinas, assim como dos teores de óleos essenciais, cinzas totais, umidade e pH, demonstrando que os aspectos ambientais influenciam o metabolismo de Vanillosmopsis erythrpappa. As reações para cumarinas permaneceram constantes e as reações para alcalóides e antraquinonas não foram positivas. As médias anuais dos valores obtidos foram: óleos essenciais $=0,29 \pm 0,09 \%$; cinzas totais $=3,13 \pm 0,49 \%$; umidade $=6,56 \pm 0,80 \%$ e $\mathrm{pH}=5,40 \pm 0,24$.

\section{Materiais e Métodos}

Coleta do material: A espécie Vanillosmopsis erythropappa Schult. Bip. foi coletada no Campus da Universidade Federal de Juiz de Fora. A exsicata foi catalogada no Herbário Leopoldo Krieger do Departamento de Botânica da UFJF sob nº 25363. O material botânico coletado foi submetido à temperatura de 50 ${ }^{\circ} \mathrm{C}$, até a perda de 90 a $95 \%$ de sua umidade. Após seco, foi triturado em moinho, com peneiras de granulação definida e o material moído foi acondicionado em recipientes de vidro ${ }^{6,10}$.

Pesquisa de classes de substâncias do metabolismo secundário: As pesquisas das classes de substâncias do metabolismo secundário foram realizadas através de reações gerais ${ }^{6}$ : flavonóides (reação com $\mathrm{AlCl}_{3}$, com $\mathrm{H}_{3} \mathrm{BO}_{3}$, com $\mathrm{NaOH} 1 \mathrm{~N}$, reação de Shinoda), taninos (reação com acetato de chumbo, com alcalóides, com gelatina, com sais de cobre e com sais de ferro), cumarinas (reação com KOH $2 \mathrm{~N}$ ), triterpenóides e esteróides (reação de Kedde, reação de Liberman-Buchard, reação de Baljet), saponinas (índice de espuma), alcalóides (reação de Bertrand, de Bouchardat, de Dragendorf e de Mayer) 
e antraquinonas (reação de Borntraeger).

Determinação do teor de óleo essencial: $O$ teor de óleo essencial foi determinado por hidrodestilação a vapor; $50 \mathrm{~g}$ de galhos secos triturados foram transferidos para um balão e adicionado $1000 \mathrm{ml}$ de água destilada. O balão foi acoplado ao aparelho de Clevenger e aquecido por uma manta elétrica, até fervura, prolongando-se por 3 horas. Três medidas de óleo essencial foram realizadas em cada mês s $^{5,10}$.

Determinação do teor de cinzas totais: Em um cadinho previamente calcinado a $600{ }^{\circ} \mathrm{C}$ por 1 hora, foi colocado $3 \mathrm{~g}$ de galhos secos triturados, incinerando-os a $450^{\circ} \mathrm{C}$, durante 4 horas em mufla. Calculou-se o teor de cinzas totais pela diferença entre o peso do conjunto cadinho e a amostra antes e após a incineração ${ }^{5,10}$. Três medidas de cinzas totais foram realizadas em cada mês.

Determinação do teor de umidade: Foi pesado $1 \mathrm{~g}$ dos galhos secos triturados em um prato de alumínio, que foi submetido à secagem por infravermelho durante 10 minutos a uma temperatura de $100{ }^{\circ} \mathrm{C}$, no sistema de secagem infra-vermelho Gehaka BG200. $\mathrm{O}$ teor de umidade foi determinada através da leitura automatizada do equipamento. Três medidas de umidade foram realizadas em cada mês.

Determinação do pH: Um extrato aquoso foi preparado a partir de $1 \mathrm{~g}$ em $10 \mathrm{ml}$ de água destilada. Transcorridos 10 minutos, esse extrato foi filtrado com algodão para um becker de $10 \mathrm{ml}$, sendo efetuada a leitura em um pHmetro digital da marca Mettler Toledo modelo MP 220. O resultado final foi calculado através da média aritmética de 3 leituras.

\section{Referências}

${ }^{1}$ Barroso, G.M. Sistemática de angiospermas do Brasil. Viçosa, MG: Imprensa Universitária/UFV, v. 3, p. 237-275, 1986.

${ }^{2}$ Bohlmann, F.; Zdero, C.; Robison, H.; King, R. Germacranolides from Piptolepsis ericoides and Vanillosmopsis species. Phytochemistry, v. 20, n. 4, p. 731-734, 1981.

${ }^{3}$ CETEC - Fundação Centro Tecnológico de Minas Gerais. Ecofisiologia da candeia. Belo Horizonte, SAT/CETEC, p. 163, 1996.

${ }^{4}$ Cruz, G.L. Dicionário das plantas úteis do Brasil, 5. ed., Bertrand Brasil, p. 599, 1995.

${ }^{5}$ Farmacopéia Brasileira. 4. ed. Rio de Janeiro: Atheneu, v. 1, 1988.

${ }^{6}$ Matos, F.J.A. Introdução a fitoquímica experimental. Fortaleza: Edições UFC, 141p. 1997.

7 Pires, F.R.S. Árvores de Ibitipoca: Vanillosmopsis erythropappa. Guia da Serra. 6. ed., Ano III, 8p.,2000.

${ }^{8}$ Silvério, M.S.; Sousa, O.V.; Leite, M.N. Análise fitoquímica das inflorescências de Vanillosmopsis erythropappa. VIII Seminário de iniciação científica da UFJF. Resumo, p. 226, 2000.

${ }^{9}$ Silvério, M.S.; Sousa, O.V.; Leite, M.N. Phytochemistry screening and toxicity of Vanillosmopsis erythropappa. Europ. J. Pharmaceutical Sciences, v. 13, n. 1, p. 103-104, 2001.

${ }^{10}$ Simões, C.M.O.; Sckenkel, E.P.; Gosmann, G.; Mello, J.C.P.; Mentez, L.A.; Petrovick, P.R. Farmacognosia: da planta ao medicamento. 2. ed., Porto Alegre/Florianópolis: Ed.
Universidade/UFRGS/ Ed. da UFSC, 821p., 2000.

${ }^{11}$ Sousa, M.P.; Matos, M.E.O.; Matos, F.J.A.; Machado, M.I.L.E.; Craveiro, A.A. Constituintes químicos ativos de plantas medicinais brasileiras. Fortaleza: Edições UFC, 416p., 1991.

${ }^{12}$ Sousa, O.V.; Silvério, M.S.; Oliveira, I.C.M.; Mattos, M.C.; Benchtrit, L.C.; Kaplan, M.A.C. Atividade antibacteriana de inflorescências de Vanillosmopsis erythropappa, Asteraceae. III Simpósio brasileiro de farmacognosia. Resumos. p. AB-27, 2001.

${ }^{13}$ Strayer, L. Bioquímica. 4. ed., Rio de Janeiro: Guanabara Koogan, 1000p., 1996.

${ }^{14}$ Vichnewski, W., Takahashi, A.M., Nasi, A.M.T., Gonçalves, D.C. R.G., Dias, D.A., Lopes, J.N.C., Goedken, V.L., Gutierrez, A.B., Herz, W. Sequiterpene lactones and the other constituents from Eremanthus seidelii, E. goyazensis and Vanillosmoposis erythropappa. Phytochemistry, v. 28, n. 5, p. 1441-1451, 1989.

*Autor para correspondência:

Prof. Dr. Orlando Vieira de Sousa

Departamento Farmacêutico

Faculdade de Farmácia e Bioquímica

Universidade Federal de Juiz de Fora.

Campus Universitário - Bairro Martelos

CEP 36036-330 - Juiz de Fora (MG)

E-mail: orlando@fbio.ufjf.br ou ovsousa@uol.com.br. 